\title{
The changing face of family medicine
}

$\mathrm{T}$

he idea that someone could be a generalist-specialist seems like the ultimate oxymoron, if not the punch line to a bad joke. But for advocates of primary care, the topic is no laughing matter. Family medicine is becoming more specialized in Canada, as more and more general practitioners narrow the scopes of their practices to focus on areas they are particularly interested in. This trend has prompted some to ponder a question that is getting harder to answer with each passing year: What, exactly, is a family physician?

"In a rapidly changing health care environment, family medicine is struggling for a clear identity - a matter which is crucial to health system restructuring because it affects the roles and functioning of other professions in the system," stated a study of perceptions of family medicine led by Dr. Marie-Dominique Beaulieu, a family physician and professor in the Department of Family Medicine at the Université de Montréal in Québec (Soc Sci Med 2008;67:1153-63).

In the 2010 National Physician Survey, $30.55 \%$ of general practitioners reported having focused practices. The most popular areas of focus are emergency medicine $(25.8 \%)$, geriatric medicine $(9.1 \%)$ and obstetrics $(8.9 \%)$. Others include palliative care $(5.9 \%)$ and anesthesia (5\%).

Even among family doctors who don't restrict their practices, the vast majority still have areas of special interest - probably somewhere in the neighbourhood of $80 \%$, according to Dr. Cal Gutkin, executive director and chief executive officer of the College of Family Physicians of Canada.

"This is a normal part of family practice," says Gutkin. "It is much more common than uncommon for a physician to have one or more areas where they develop a special interest. Some take continuing medical education or enhance their skills in certain areas."

The trend of specialization started

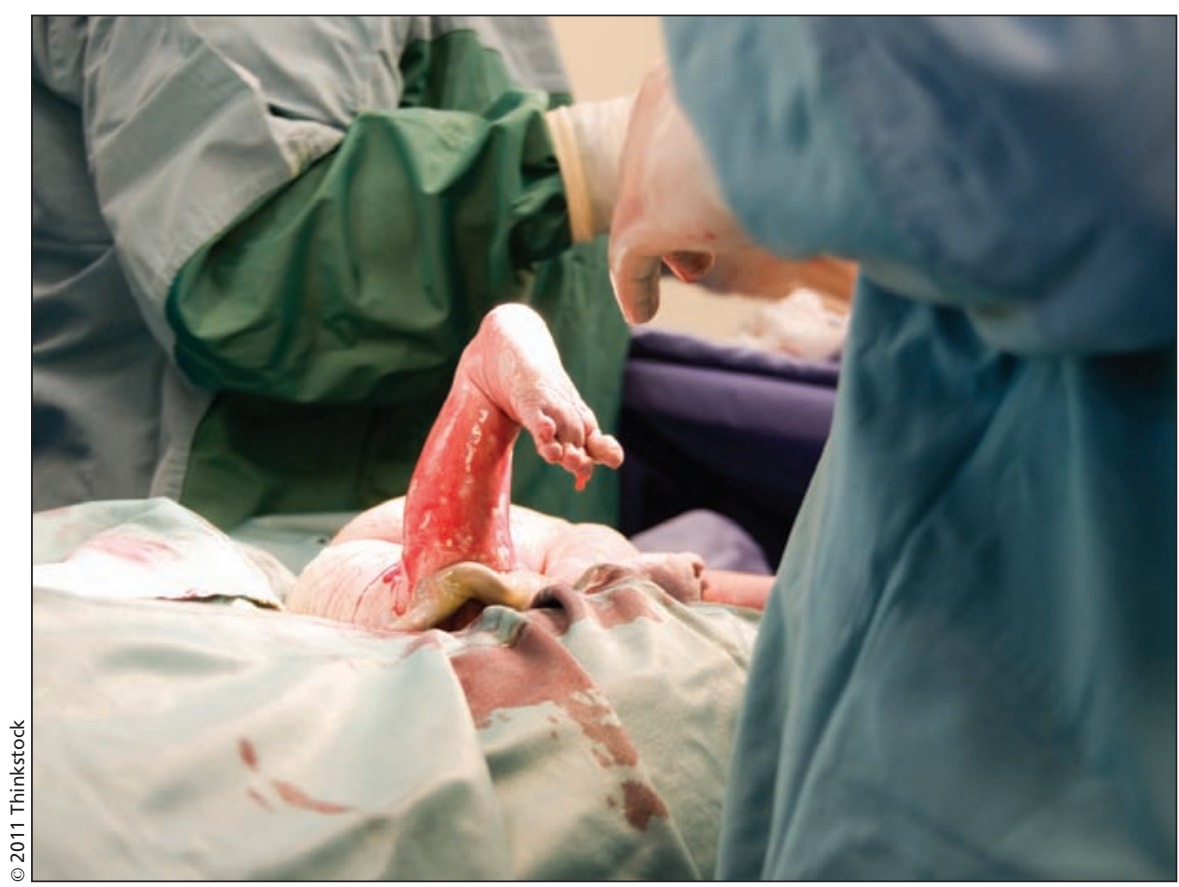

Some general practitioners now perform procedures, such as cesarian sections, once considered the domain of specialists.

two or three decades ago, says Gutkin. And though the college offers support to family physicians with special interests, it does not promote the narrowing of the overall scope of primary care in Canada. "We want a future where more family physicians can incorporate their special interests as part of family practice," he says. "Our goal is to bring them back under the roof of comprehensive care."

The college recently introduced a number of programs in its Section of Family Physicians with Special Interests or Focused Practices (www.cfpc .ca/SIFP). Each program focuses on a particular type of care, such as addiction medicine and mental health, and has a committee with mandates that include fostering continuing professional development and facilitating communication between physicians with the same interests.

One thing these programs will definitely not do is create subspecialties in family medicine, emphasizes Dr. Rob Boulay, president of the College of
Family Physicians of Canada. "I want to firmly state that we have one specialty and that specialty is family medicine," says Boulay. "We do not want to entertain language that includes 'subspecialty.' This is not a route to subspecialty. We in no way want people to think we are pursuing this to provide our members with subspecialties."

Whether or not new titles are granted, the trend toward more specialized general practitioners seems likely to continue, Beaulieu et al. suggested in their study of the changing identity of family medicine. In Canada, as in countries such as France and Belgium, doctors are becoming less interested in being pure generalists. "A growing proportion of general practitioners are restricting their practice, which diminishes access to primary care providers, particularly in rural and remote regions," the paper states.

Others within the field of primary care aren't as concerned about the rise of specialization, suggesting that it 
increases the number of services available to patients, particularly in teambased practices, and reduces wait times for some procedures typically performed only by specialists.

Some physicians posit that, in an era where scientific and medical knowledge grows exponentially, it is unrealistic to expect a single physician to provide care that is truly comprehensive, the paper notes, while other generalists believe that both the public and the medical profession place a much higher value on the work of specialists. "For family physicians - residents or educators — the recognition accorded to specialization is an irritant and a constant source of concern," the paper states.

Beaulieu and her colleagues conducted focus groups and interviews with a wide range of people: general practitioners, family medicine trainees, consultants and patients. Two general characteristics of family medicine emerged: large scope of practice and long-term relationships with patients. But when it came to specifics, answers were anything but consistent. "The results highlighted that neither the general public nor the professionals had a clear understanding of what family medicine represents." - Roger Collier, CMAJ

CMAJ 2011. DOI:10.1503/cmaj.109-4036

Editor's note: First of a three-part series

Part II: A comprehensive view of focused practices

(www.cmaj.ca/lookup/doi/10.1503

/cmaj.109-4040).

Part III: Potential pitfalls of "specialized" primary care

(www.cmaj.ca/lookup/doi/10.1503

/cmaj.109-4044). 